59. Lucey EC, Goldstein RH, Breuer R, et al. Retinoic acid does not affect alveolar septation in adult FVB mice with elastase-induced emphysema. Respiration 2003;70:200-5.

60. March TH, Bowen LE, Finch GL, et al. Effects of strain and treatment with inhaled all-trans-retinoic acid on cigarette smoke-induced pulmonary emphysema in mice. COPD 2005;2:289-302

61. March TH, Cossey PY, Esparza DC, et al. Inhalation administration of all-transretinoic acid for treatment of elastase-induced pulmonary emphysema in Fischer 344 rats. Exp Lung Res 2004;30:383-404.

62. Meshi B, Vitalis TZ, lonescu D, et al. Emphysematous lung destruction by cigarette smoke. The effects of latent adenoviral infection on the lung inflammatory response. Am J Respir Cell Mol Biol 2002;26:52-7.

63. Nishi Y, Boswell V, Ansari $T$, et al. Elastase-induced changes in lung function: relationship to morphometry and effect of drugs. Pulm Pharmacol Ther 2003;16:221-9.
64. Srinivasan G, Bruce EN, Houtz PK, et al. Dexamethasone-induced changes in lung function are not prevented by concomitant treatment with retinoic acid. Am J Physio Lung Cell Mol Physiol 2002;283:L275-87.

65. Stinchcombe SV, Maden M. Retinoic acid-induced alveolar regeneration: critical differences in strain sensitivity. Am J Respir Cell Mol Biol 2008;38:185-91.

66. Yang L, Naltner A, Yan C. Overexpression of dominant negative retinoic acid receptor alpha causes alveolar abnormality in transgenic neonatal lungs. Endocrinology 2003; 144:3004-11

67. Shenai JP, Kennedy KA, Chytil F, et al. Clinical trial of vitamin A supplementation in infants susceptible to bronchopulmonary dysplasia. J Pediatr 1987;111:269-77.

68. Morabia A, Menkes MJ, Comstock GW, et al. Serum retinol and airway obstruction. Am J Epidemiol 1990;132:77-82.

69. Roth MD, Connett JE, D'Armiento JM, et al. Feasibility of retinoids for the treatment of emphysema study. Chest 2006;130:1334-45.

\title{
Pulmonary puzzle
}

\begin{abstract}
ANSWERS
From the questions on page 398

The combination of cystic lung disease, a family history of lung disease and the characteristic papular lesions on this patient are highly suggestive of Birt-Hogg-Dube syndrome (BHDS). Genetic sequencing of the folliculin (FLCN) gene identified a novel frameshift mutation and confirmed the presence of BHDS.

Cystic lung disease occurs in a relatively narrow disease spectrum including lymphangioleimyomatosis/tuberous sclerosis complex, Langerhans cell histiocytosis, lymphocytic interstitial pneumonia, neurofibromatosis, Marfan's syndrome, Ehlers-Danlos syndrome (EDS), $\alpha_{1}$ antitrypsin deficiency, Pneumocystis jirovecii infection and BHDS. This patient's strong family history across several generations suggested an autosomal-dominant process such as neurofibromatosis, Marfan's syndrome, EDS or BHDS. While he did not have the phenotypic characteristics of neurofibromatosis, Marfan's syndrome or EDS, his skin lesions appeared typical for BHDS. Diagnostic evaluation therefore proceeded to confirm BHDS.

BHDS was initially described in 1977 as an autosomal-dominant disorder of benign skin tumours including fibrofolliculomas, trichodiscomas and acrochordons. ${ }^{1}$ Subsequent studies have shown that mutations in the FLCN gene are responsible for BHDS and the gene is highly expressed in skin, kidney and lung stromal cells and type I pneumocytes. ${ }^{2}$ A genotype-phenotype association has been reported between the degree of cystic lung disease, the risk of spontaneous pneumothorax and the exonic location of the FLCN mutation. ${ }^{3}$

Although pneumothoraces in BHDS can be associated with morbidity, mortality may be increased in BHDS due to the development of renal tumours (oncocytic hybrid tumours, chromophobe renal cell carcinoma, clear cell carcinoma, papillary renal cell carcinoma). ${ }^{4}$ In a cross-sectional analysis of 98 patients with BHDS, the age-adjusted odds ratio for the development of renal cell carcinoma was 6.9, with chromophobe renal cell carcinoma being the most common cell type. ${ }^{5}$

Thus, BHDS consists of characteristic benign skin lesions, cystic lung disease with spontaneous pneumothorax and a risk of renal cell carcinoma. Owing to the potential mortality associated with renal tumours, an annual abdominal CT scan is recommended to evaluate the development of these tumours. Furthermore, due to incomplete skin lesion penetrance, family members should be screened with genetic testing or renal ultrasound to check for renal tumours and genetic counselling should be provided to couples planning to have children.
\end{abstract}

Thorax 2009;64:457. doi:10.1136/thx.2008.102095a

\section{REFERENCES}

1. Birt AR, Hogg GR, Dube WJ. Hereditary multiple fibrofolliculomas with trichodiscomas and acrochordons. Arch Dermatol 1977:113:1674-7.

2. Nickerson ML, Warren MB, Toro JR, et al. Mutations in a novel gene lead to kidney tumors, lung wall defects, and benign tumors of the hair follicle in patients with the Birt-Hogg-Dube syndrome. Cancer Cell 2002;2:157-64.

3. Toro JR, Pautler SE, Stewart L, et al. Lung cysts, spontaneous pneumothorax, and genetic associations in 89 families with BirtHogg-Dube syndrome. Am J Respir Crit Care Med 2007;175:1044-53.

4. Pavlovich CP, Grubb RL 3rd, Hurley K, et al. Evaluation and management of renal tumors in the Birt-Hogg-Dube syndrome. J Urol 2005:173:1482-6.

5. Zbar B, Alvord WG, Glenn G, et al. Risk of renal and colonic neoplasms and spontaneous pneumothorax in the Birt-Hogg-Dube syndrome. Cancer Epidemiol Biomarkers Prev 2002;11:393-400. 